\title{
ОБЕСПЕЧЕНИЕ ПРАВ ГРАЖДАН ЕС В КОНТЕКСТЕ БРЕКЗИТА
}

\begin{abstract}
Аннотация. В статье рассматривается ситуация с обеспечением прав граждан Европейского союза, проживающих в Великобритании, и британцев, проживающих в странах Евросоюза, после выхода Соединённого Королевства из ЕС. На основании офиииальных документов Евросоюза и Великобритании автор выявляет различия, которые ожидают граждан ЕС, в случае выхода страны с соглашением или без него. В первом случае граждане Евросоюза, проживающие в Великобритании, должны получить права, практически идентичные тем, которые они имели бы в рамках действующего членства страны в ЕС. Во втором, при сохранении значительного объёма прав, британское правительство намерено ограничить сроки их получения, а следовательно, и число потенциальных претендентов. В отночении британских граждан в Евросоюзе, вероятно, будет применяться принцип взаимности.
\end{abstract}

Ключевые слова: брекзит, Европейский союз, Великобритания, права граждан, соглашение о выходе, иммиграционная политика, выход «без сделки».

Выход Великобритании из Европейского союза затронет экономику государства и каждодневную жизнь жителей страны. Но более 4,5 млн человек окажутся в совершенно новой для себя ситуации. Существование свободы передвижения в рамках Единого внутреннего рынка (ЕВР) ЕС привело к тому, что 3,7 млн граждан стран Евросоюза живёт и работает в Соединённом Королевстве, и более одного миллиона британских подданных проживает в других странах EC ${ }^{1}$. После того как Британия покинет ЕС, их статус изменится. Поэтому на переговорах о выходе Европейский союз обозначил проблему соблюдения прав граждан как одну из важнейших ${ }^{2}$. Первоначальные позиции сторон сильно различались, однако, как ни странно, удалось достичь взаимоприемлемых для всех условий. Британия и ЕС пошли на взаимные уступки, более серьёзные - с британской стороны. В итоге в подписанном соглашении о выходе права граждан Евросоюза, проживающих в Великобритании, оказались надёжно защищены. Однако сложности с ратификацией соглашения в Палате общин могут привести к тому, что Соединённое Королевство покинет ЕС «без сделки», и тогда вопрос с обеспечением прав граждан Европейского союза в Великобритании и британцев в странах ЕС станет вновь актуальным.

(C) Бабынина Людмила Олеговна - кандидат политических наук, ведущий научный сотрудник, руководитель Центра политической интеграции ИЕ РАН. Адрес: 125009, Россия, Москва, ул. Моховая, д. 11, стр. 3; доцент факультета мировой политики МГУ им. М.В. Ломоносова. E-mail: lbabynina@yandex.ru.

DOI: http://dx.doi.org/10.15211/vestnikieran120192429

${ }^{1}$ Согласно данным статистики 785 тыс. британцев проживает в континентальных странах ЕС и 277 тыс. зарегистрированы резидентами в Ирландии. Migration Statistics. Briefing Paper. House of Commons Library. Number SN06077, 11.12.2018. P. 27, 30. URL: https://researchbriefings.parliament.uk/ResearchBriefing/Summary/SN06077.

${ }^{2}$ European Council (Art. 50) guidelines following the United Kingdom's notification under Article 50 TEU. URL: http://www.consilium.europa.eu/en/press/press-releases/2017/04/29-euco-brexit-guidelines/ 


\section{Если Соглашение о выходе Соединённого Королевства из Европейского союза вступит в силу}

Если Соглашение о выходе Соединённого Королевства из ЕС ${ }^{1}$ вступит в силу, то до 31 декабря 2020 г. будет действовать переходный период, и новые правила станут актуальными с 1 января 2021 г. Они будут распространяться не только на граждан Евросоюза, но и на граждан всех стран Европейского экономического пространства (ЕЭП) и Швейцарии. Со странами ЕАСТ Великобритания в настоящее время проводит переговоры для согласования положений аналогичных соглашению с ЕС.

Что же будет гарантировано гражданам ЕC, проживающим и работающим в Великобритании, согласно ещё не ратифицированному договору?

Те, кто прожили в стране пять лет, могут получить статус поселенца. Это новая для Великобритании форма для иностранцев, придуманная специально для граждан ЕС, попадающих под действие брекзита. Данный статус может быть получен упрощённым путём в сравнении с другими иммиграционными форматами. Изначально предполагалось, что процедура будет платной, но ввиду сложностей с ратификацией Соглашения о выходе Тереза Мэй допустила возможность сделать её бесплатной для того, чтобы иметь козыри в будущих переговорах с Евросоюзом. Данная схема будет действовать в течение полугода после окончания переходного периода, то есть до июля 2021 г. $^{2}$ Те, кто приехал в Соединённое Королевство до окончания переходного периода, но не успел прожить там пять лет, получат возможность «дожить» необходимое время и потом подать заявку на получение статуса поселенца.

Граждане Европейского союза и их семьи, включая детей, родившихся после даты выхода Великобритании, и близких родственников, не имеющих гражданства ЕС, получат пожизненные гарантии соблюдения своих прав в соответствии с текущими правилами в сфере социального, пенсионного и медицинского обеспечения. Они смогут работать, учиться и открывать бизнес в Соединённом Королевстве на тех же условиях, как в настоящее время. Граждане ЕС, отсутствующие на территории Соединённого Королевства в течение пяти лет, будут лишены статуса поселенца. Трансграничные работники (граждане ЕС, не являющиеся британскими резидентами, но приезжающие на работу в Соединённое Королевство) будут продолжать работать по существующим правилам, если они начали свою деятельность до окончания переходного периода.

Следить за соблюдением прав граждан Евросоюза в Соединённом Королевстве будет специально созданный совместный Комитет, который сможет обращаться в суд ЕС за толкованием законов в течение восьми лет. А для британских судов решения Суда ЕС станут обязательными при вынесении решений. В этом вопросе на уступки пошел Европейский союз, отказавшись от требований прямой юрисдикции Суда ЕС в вопросах соблюдения прав граждан.

Особый статус на территории Соединённого Королевства будет гарантирован для граждан Республики Ирландия. Страны сохранят существующую Общую зону передвижения (Common Travel Area) и свободу передвижения внутри неё Граждане Ирландии не должны будут получать статус поселенца, они смогут, как и в настоящее время, жить, работать и учиться на территории Великобритании без оформления специального иммиграционного разрешения. Родившиеся в Северной Ирландии сохранят возможность выбирать британское или

\footnotetext{
${ }^{1}$ Agreement on the withdrawal of the United Kingdom of Great Britain and Northern Ireland from the European Union and the European Atomic Energy Community. URL: https://www.consilium.europa.eu/media/37099/ draft withdrawal_agreement_incl_art132.pdf.

${ }^{2}$ HM Government. The UK's future skills-based immigration system. December 2018. URL:_https://assets.publishing. service.gov.uk/government/uploads/system/uploads/attachment_data/file/766672/The-UKs-future-skills-based-immigra tion-system-accessible-version.pdf.
}

Научно-аналитический вестник ИЕ РАН, 2019, №1 
ирландское гражданство, или брать двойное.

Великобритания и Европейский союз не предполагают в будущем вводить визы для краткосрочных поездок. Республика Ирландия подтвердила, что для поддержания Общей зоны передвижения останется вне Шенгенского пространства, но полностью сохранит своё участие в Едином внутреннем рынке ЕС, включая свободу передвижения. Таким образом, граждане Евросоюза, приехавшие в Ирландию, смогут посетить Соединённое Королевство с краткосрочным визитом, но не будут иметь право там работать или учиться без оформления специального разрешения.

Подданные Её Величества после выхода Великобритании из ЕС потеряют гражданство Европейского союза и право свободного передвижения по его территории. То есть при переезде из страны постоянного проживания в другую страну ЕС на длительное время, их права не будут автоматически гарантированы. Однако в стране постоянного проживания граждане Великобритании получат в целом такой же доступ к здравоохранению, пенсиям и другим пособиям, как и в настоящее время. Если они получили соответствующий статус резидента, то у них будет возможность покинуть страну проживания в ЕС на срок до пяти лет без потери права на возвращение.

По окончании переходного периода с 2021 г. в Великобритании будет введена в действие новая иммиграционная система ${ }^{1}$, в основе которой лежит идея привлечения высококвалифицированных работников в страну, вне зависимости от их национальной принадлежности. Таким образом, будут ликвидированы преимущества, которыми в настоящее время обладают граждане ЕС в рамках ЕВР.

\section{Если Великобритания выходит «без сделки»}

Если подписанное соглашение не будет ратифицировано и Великобритания выйдет «без сделки», ситуация с правами граждан ЕС в Соединённом Королевстве и британцев в странах Евросоюза будет серьёзно отличаться от описанного выше.

Выход без соглашения означает отмену транзитного периода. Поэтому гарантии соблюдения прав будут применимы только к тем гражданам Евросоюза, которые въехали на территорию Соединённого Королевства до 29 марта 2019 г. ${ }^{2}$ Они и члены их семей смогут до 31 декабря 2020 г. подать заявку на оформление статуса поселенцев, но дополнительный период в полгода будет отменён. Новая иммиграционная система, как и планировалось, вступит в силу с 1 января 2021 г. для граждан ЕС, получивших статус поселенца, предусмотрена возможность воссоединяться с близкими родственниками (если отношения родства были оформлены до 29 марта 2019 г.) по существующим в настоящее время правилам до 29 марта 2022 г. После этой даты воссоединение семей будет осуществляться согласно иммиграционному законодательству Великобритании.

Граждане ЕС и члены их семей, законно проживающие в Великобритании к моменту выхода страны из Евросоюза, получат такой же широкий доступ программам социального обеспечения и государственным услугам, как и в настоящее время. Эти программы охватывают здравоохранение, образование, пособия, социальное жильё и другие. Изменение данных прав будет осуществляться одинаково для граждан ЕС и граждан Великобритании. Британ-

\footnotetext{
${ }^{1}$ HM Government. The UK's future skills-based immigration system. December 2018. URL: https://assets.publishing. service.gov.uk/government/uploads/system/uploads/attachment_data/file/766672/The-UKs-future-skills-based-immigra tion-system-accessible-version.pdf. См. также: Годованюк К.А. Контуры новой иммиграционной политики Соединённого Королевства. Научно-аналитический вестник ИЕ РАН. №6, 2018. С. 106-111.

${ }^{2}$ Citizens' Rights - EU citizens in the UK and UK nationals in the EU. Policy Paper. URL: https://assets.publishing. service.gov.uk/government/uploads/system/uploads/attachment_data/file/762222/Policy_paper_on_citizens__rights_in_ the_event_of_a_no_deal_Brexit.pdf.
}

Научно-аналитический вестник ИЕ РАН, 2019, №1 
ские власти гарантируют признание квалификации граждан Евросоюза, если они подали заявку и получили решение о признании 29 марта 2019. В отношении своих граждан, проживающих в странах ЕС, британское правительство выступает за применение принципа взаимности.

Британский Хоум Офис опубликовал руководство к действию для граждан Европейского экономического пространства, включая граждан ЕС, и Швейцарии, если они хотят находиться в Соединённом Королевстве, в случае отсутствия соглашения о выходе ${ }^{1}$. До трёх месяцев граждане ЕЭП могут находиться на территории Великобритании без оформления визы или иммиграционных документов. Те, кто рассчитывает на более длительное пребывание, должны будут оформить новый статус. Если граждане ЕЭП прибыли в страну до момента выхода из Евросоюза, то они могут подать запрос на получение статуса поселенца. Те же, кто приедет после 29 марта 2019 г., но до 1 января 2021 г. с целью жить, работать или учиться в Великобритании, должны будут оформить специальное разрешение на временное пребывание (European Temporary Leave to Remain), которое будет действовать в течение трёх лет. По истечению этого периода они будут попадать под действие новой иммиграционной системы. Близкие члены семей граждан ЕЭП из третьих стран не смогут автоматически присоединиться к ним в Великобритании, а должны будут получить специальное разрешение на воссоединение.

Положение британцев в странах Евросоюза в случае выхода «без сделки» во многом будет зависеть от гарантий, которые предоставит каждая из стран. Нужно отметить, что в целом государства ЕС заинтересованы сохранить присутствие британцев на своей территории, но объём предоставляемых прав сильно отличается. Например, Нидерланды готовы предоставить британским гражданам режим наибольшего благоприятствования, а Польша и Испания настаивают на применении принципа зеркальности ${ }^{2}$. Во всех странах Евросоюза после выхода британцы больше не будут иметь права на автоматическое возмещение местных расходов на здравоохранение Национальной службой здравоохранения Великобритании ${ }^{3}$. Это может быть особенно важно для британских пенсионеров, проживающих в странах ЕС.

Сохранить существующие права и оградить себя от последствий выхода Великобритании из ЕС пытаются и сами граждане Европейского союза через процедуру получения второго гражданства. Так число запросов на получение британского гражданства гражданами ЕС выросло на 200\% с 2015 по 2018 гг. Похожую динамику демонстрируют и запросы на получение второго гражданства со стороны британских подданных. Наибольшей популярностью у них пользуются Германия, Швеция, Франция и Бельгия ${ }^{4}$.

\section{Выводы}

В подписанном соглашении о выходе обеспечение прав граждан стало одним из важнейших разделов. Выполнив некоторые формальности, граждане ЕС и члены их семей, проживающие в Великобритании, сохранят имеющиеся у них права практически в полном объёме. Британцы, проживающие в Евросоюзе, также сохранят свои права в стране проживания, но потеряют право на свободу передвижения на территории ЕС.

\footnotetext{
${ }^{1}$ Home Office. European Temporary Leave to Remain in the UK. URL: https://www.gov.uk/guidance/europeantemporary-leave-to-remain-in-the-uk.

${ }^{2}$ Citizens' rights for Brits in the EU if there's no Brexit deal. Politico. URL: https://www.politico.eu/article/citizensrights-for-brits-in-the-eu-if-theres-no-brexit-deal/https:/www.politico.eu/article/citizens-rights-for-brits-in-the-eu-iftheres-no-brexit-deal/

${ }^{3}$ The Guardian. UK retirees in EU will lose free healthcare under no-deal Brexit. URL: https://www.theguardian. com/politics/2019/jan/29/british-pensioners-in-eu-will-lose-nhs-covered-health-care-under-no-deal-brexit.

${ }^{4}$ Citizens' rights for Brits in the EU if there's no Brexit deal. Politico. URL: https://www.politico.eu/article/citizensrights-for-brits-in-the-eu-if-theres-no-brexit-deal/https:/www.politico.eu/article/citizens-rights-for-brits-in-the-eu-iftheres-no-brexit-deal/
} 
Однако если соглашение не будет ратифицировано, ситуация с правами граждан Европейского союза изменится. В целом Великобритания не отказывается сохранить имеющиеся у граждан ЕС права, но ограничит возможность их получения по времени. Отсутствие транзитного периода сокращает сроки, которые могут быть использованы для получения статуса поселенца, который гарантирует сохранение существующих прав для граждан ЕС. Приехавшие после выхода смогут получить лишь временный статус, а по его истечении будут попадать под действие новой иммиграционной системы страны, которая будет основана на идее привлечения высококвалифицированных специалистов и не будет делать различия между гражданами Европейского союза и других стран.

Британское правительство надеется на применение зеркальных мер к своим гражданам, проживающим в странах ЕС. Однако сохранение существующих прав британских подданных в странах Евросоюза будет отличаться от страны к стране и не будет гарантировано при переезде в другое государство ЕС. Опасения, существующие у граждан, нашли отражение в росте заявок на получение второго гражданства.

\section{Список литературы}

Годованюк К.А. Контуры новой иммиграционной политики Соединённого Королевства. Научно-аналитический вестник ИЕ РАН. №6, 2018. С. 106-111. URL: http://vestnikieran.institu teofeurope.ru/images/\%D0\%B3\%D0\%BE\%D0\%B4\%D0\%BE\%D0\%B2\%D0\%B0\%D0\%BD\%D1 \%8E\%D0\%BA_6_2018.pdf.

\section{References}

Agreement on the withdrawal of the United Kingdom of Great Britain and Northern Ireland from the European Union and the European Atomic Energy Community. URL: https://www.consili um.europa.eu/media/37099/draft_withdrawal_agreement_incl_art132.pdf.

Citizens' Rights - EU citizens in the UK and UK nationals in the EU. Policy Paper. URL: https://assets.publishing.service.gov.uk/government/uploads/system/uploads/attachment_data/file/7 62222/Policy_paper_on_citizens_rights_in_the_event_of_a_no_deal_Brexit.pdf.

Citizens' rights for Brits in the EU if there's no Brexit deal. Politico. URL: https://www.politico.eu/article/citizens-rights-for-brits-in-the-eu-if-theres-no-brexitdeal/https://www.politico.eu/article/citizens-rights-for-brits-in-the-eu-if-theres-no-brexit-deal/

Council of the European Union. Annex to the Council Decision. Brussels, 29 January 2018. URL: http://www.consilium.europa.eu//media/32504/xt21004-ad01re02en18.pdf.

EEA migration in the UK: Final report Migration Advisory Committee. September 2018. URL: https://assets.publishing.service.gov.uk/government/uploads/system/uploads/attachment_data/file/7 41926/Final_EEA_report.pdf.

European Council (Art. 50) (23 March 2018) - Guidelines. URL: http://www.consilium. europa.eu/media/33458/23-euco-art50-guidelines.pdf.

European Council (Art. 50) guidelines following the United Kingdom's notification under Article 50 TEU. URL: http://www.consilium.europa.eu/en/press/press-releases/2017/04/29-euco-brexitguidelines/

Godovanyuk K.A. Kontury novoj immigracionnoj politiki Soedinennogo Korolevstva. (The New Contours of UK Migration Policy). Nauchno-analiticheskij vestnik IE RAN. №6, 2018. P. 106-111. URL: http://vestnikieran.instituteofeurope.ru/images/\%D0\%B3\%D0\%BE\%D0\%B4\%D0 \%BE\%D0\%B2\%D0\%B0\%D0\%BD\%D1\%8E\%D0\%BA_6_2018.pdf. 
HM Government. The UK's future skills-based immigration system. December 2018. URL: https://assets.publishing.service.gov.uk/government/uploads/system/uploads/attachment_data/file/7 66672/The-UKs-future-skills-based-immigration-system-accessible-version.pdf.

Home Office. European Temporary Leave to Remain in the UK. URL: https://www.gov.uk/ guidance/european-temporary-leave-to-remain-in-the-uk.

Migration Statistics. Briefing Paper. House of Commons Library. Number SN06077, 11 December 2018. URL: https://researchbriefings.parliament.uk/ResearchBriefing/Summary/SN06077.

\section{Ensuring the EU citizens' rights in the context of Brexit}

Author. Liudmila Babynina, Candidate of Sciences (Politics), Head of the Center for Political Integration studies, Institute of Europe, Russian Academy of Sciences. Address: 11-3, Mokhovaya str., Moscow, Russia, 125009. Associate Professor, Faculty of the World Politics Lomonosov Moscow State University. E-mail: lbabynina@yandex.ru.

Abstract. The article deals with the issue of ensuring the rights of EU citizens living in the UK and Britons living in the EU countries after Brexit. On the basis of official documents of the European Union and the UK the author reveals the differences that await EU citizens in the event of the country's withdrawal with or without an agreement. In the first case, EU citizens residing in the UK must obtain rights that are almost identical to those they would have within the country's current EU membership. In the second case, while maintaining a significant amount of rights, the British government intends to limit the timing of their receipt and therefore the number of potential applicants. The principle of reciprocity is likely to be applied to British citizens in the European Union.

Key words: Brexit, European Union, United Kingdom, citizens' right, withdrawal agreement, migration policy.

DOI: http://dx.doi.org/10.15211/vestnikieran120192429 